\title{
Quantitative Electron Probe Microanalysis of Si-Ge Reference Materials
}

\author{
R. B. Marinenko, S. Turner, D. E. Newbury, L. Richter, L. Yu, R. Zeisler, D. Simons \\ National Institute of Standards and Technology, 100 Bureau Drive, Gaithersburg MD 20899
}

Si-Ge alloy research materials are being characterized at NIST in cooperation with the semiconductor industry for use in the quantification of Si-Ge films used for components now being used in a multitude of high-tech devices. We have tested the macro- and micro-heterogeneity of SiGe single crystal boules and 4- $\mu \mathrm{m}$ thick films of $\mathrm{SiGe}$ on $\mathrm{Si}$ with wavelength dispersive electron probe microanalysis (WD-EPMA) and have determined that these materials would make good microanalysis standards [1]. The total expanded $(\mathrm{k}=2,95 \%)$ Ge homogeneity uncertainty for five different specimens from a single-crystal SiGe14 (14 at. \% Ge) boule was $0.9 \%$ relative and for five specimens from each of the $\mathrm{SiGe} 10$ and $\mathrm{SiGe} 25$ films it was $1.3 \%$ relative or less.

We are now quantifying these materials using EPMA and bulk techniques, namely, neutron activation analysis (INAA) and inductively coupled plasma-optical emission spectroscopy (ICP-OES). Results in \% mass fraction (mf) of the bulk analyses compared to the nominal value for the SiGe14 boule are listed in Table 1. EPMA quantification of this binary system with EPMA is complicated by the large mass absorption coefficient (MAC) for $\mathrm{SiK} \alpha$ line ( $\mathrm{K}-\mathrm{L}_{2,3}$ transition) in the presence of Ge as well a significant range of values from the different MAC sources. The $\mathrm{SiK} \alpha \mathrm{X}$-ray fluoresces the $\mathrm{GeL} \alpha\left(\mathrm{L}_{3}-\mathrm{M}_{4,5}\right)$ line making this line difficult to use in quantitation especially at lower voltages where the GeL $\alpha$ line would be most useful. In addition, there are atomic number corrections for the GeK $\alpha \mathrm{X}$-ray line.

The need for homogeneous reference standards over a range of compositions between the two pure end members was clear in the M\&M 2001 paper by Carpenter in which he described the use of $\alpha$-factors from several data reduction procedures to determine the accuracy one could expect in the $20 \mathrm{keV}$ analysis of $\mathrm{GeSi}$ alloys [2]. For our characterization work the GeKa line is more useful for quantification especially for the bulk specimens we are characterizing. Initial analyses with the GeL $\alpha$ line demonstrated little consistency in results from multiple excitation potentials $(15,20$, and $25 \mathrm{keV})$, from different correction procedures, and from the $\mathrm{GeL} \alpha$ and $\mathrm{GeK} \alpha$ lines. The results reported here were calculated with Armstrong's correction procedure although the full PAP procedure was also used with similar results [3,4]. Either Heinrich's '86 ICXOM MACs or the combination of Henke's 85 and Armstrong's MACs (called LINEMU) were used and are indicated [5].

In Table 2 are the correction factors for the $\mathrm{SiK} \alpha$ and $\mathrm{GeK} \alpha \mathrm{X}$-ray lines taken from Armstrong's correction procedure using Heinrich's MACs at 15, 20, and $25 \mathrm{keV}$. There is no fluorescence correction in this system. The greatest correction is for absorption of the $\mathrm{SiK} \alpha$ line that even at $15 \mathrm{kV}$ is near the generally recommended lower limit of 0.70. There are atomic number corrections for the SiK $\alpha$ and GeK $\alpha$ X-ray lines, but the GeK $\alpha$ correction at $15 \mathrm{keV}$ is only $5 \%$ less than at $25 \mathrm{keV}$ suggesting that this line can be used at $15 \mathrm{keV}$, a reasonable compromise excitation potential for simultaneous measurements of both lines.

The average \% $\mathrm{mf}$ concentrations for $\mathrm{SiK} \alpha$ and $\mathrm{GeK} \alpha$ from WD-EPMA of 10 points from each of five specimens taken from the $\mathrm{SiGe} 14$ single-crystal boule are listed in Table 3 for three excitation potentials. The $15 \mathrm{keV}$ results for Ge are most similar to the nominal composition and to the ICP-OES results in Table 1 and the total at $15 \mathrm{keV}$ is about $100 \%$. For the $20 \mathrm{keV}$ and $25 \mathrm{keV}$ results, the $\mathrm{Si}$ and Ge concentrations are respectively about $1 \%$ and $4 \%$ greater than those determined at the lower excitation potential, and the Ge results are greater than the reported INAA values in Table 1. In the two columns on the right of Table 3 are the results of a mixed $\mathrm{keV}$ correction procedure for $\mathrm{SiK} \alpha$ at $15 \mathrm{keV}$ and $\mathrm{GeK} \alpha$ at 20 and $25 \mathrm{keV}$. Results here are consistent with the $15 \mathrm{keV}$ values. 
In Table 4 are the WD-EPMA average values from the analysis of 20 points on each of five different specimens from the SiGe10 and SiGe25 4- $\mu \mathrm{m}$ films on Si. Results are consistent for Ge at 15 and $20 \mathrm{keV}$ as well as for the mixed $\mathrm{keV}$ correction. Totals are less than $100 \%$. This may be due to the film densities that may be less than that of the standards. Energy dispersive (EDS) analyses of the films are reported in the last two columns and are, at most, $3 \%$ relative higher for the Ge in the SiGe10 film analyzed at $15 \mathrm{keV}$. Differences are primarily attributed to the use of different correction procedures since k-values determined from WDS and EDS data agreed to within $1 \%$ relative.

\section{References}

[1] R. B. Marinenko et. al , Amer. Inst. of Physics (AIP) Conf. Proc. of ULSI 2003 Meeting, Austin, TX, (2003).

[2] P. Carpenter and S. D. Cobb, Microsc. Microanal. 7 (Suppl 2) (2001) 682.

[3] J. T. Armstrong, Electron Probe Quantitation, Plenum Press, NY (1991) 261.

[4] J. L. Pouchou and F. Pichoir, Electron Probe Quantitation, Plenum Press, New York (1991) 31.

[5] K. F. J. Heinrich, Proc. $11^{\text {th }}$ Internat. Cong. on X-ray Optics and Microanal., Aug. 1986, London, CA.

Tables: All concentrations in $\% \mathrm{mf}$ with relative expanded uncertainties in parentheses.

Table 1. Bulk analysis of SiGe14 boule.

\begin{tabular}{|c|c|c|}
\hline SiGe14 Boule & \multicolumn{2}{|c|}{ Technique (\# samples) } \\
\hline Nom. Ge Comp & ICP-OES (2) & INAA (5) \\
\hline 29.61 & $29.73(0.5)$ & $30.35(1.5)$ \\
\hline
\end{tabular}

Table 2. ZAF correction factors for anal. of SiGe14 boule with ele.stds.

\begin{tabular}{|c|l|c|c|}
\hline $\mathrm{keV}$ & Element & $\mathrm{Z}$ & $\mathrm{A}$ \\
\hline 15 & $\mathrm{Si} \mathrm{K} \alpha$ & 1.0629 & 0.7199 \\
\hline & $\mathrm{Ge} \mathrm{K} \alpha$ & 0.8040 & 1.0009 \\
\hline 20 & $\mathrm{Si} \mathrm{K} \alpha$ & 1.0605 & 0.5962 \\
\hline & $\mathrm{Ge} \mathrm{K} \alpha$ & 0.8273 & 1.0018 \\
\hline 25 & $\mathrm{Si} \mathrm{K} \alpha$ & 1.0596 & 0.4878 \\
\hline & $\mathrm{Ge} \mathrm{K} \alpha$ & 0.8424 & 1.0027 \\
\hline
\end{tabular}

Table 3. Analysis of SiGe14 bulk alloy in \% mf with element standards
\begin{tabular}{|l|l|l|l|l|l|}
\hline $\begin{array}{c}\text { Sample/ } \\
\text { Ele,Line }\end{array}$ & \multicolumn{3}{|c|}{$\begin{array}{c}\text { Armstrong Correction/ } \\
\text { LineMu MACs }\end{array}$} & \multicolumn{2}{c|}{$\begin{array}{c}\text { Mixed keV } \\
\text { Armst Cor/Hein'86 MACs }\end{array}$} \\
\hline SiGe14 & $15 \mathrm{keV}$ & $20 \mathrm{keV}$ & $25 \mathrm{keV}$ & $15,20 \mathrm{keV}$ & $15,25 \mathrm{keV}$ \\
\hline $\mathrm{Si} \mathrm{K \alpha}$ & $70.88(0.6)$ & $71.35(0.8)$ & $71.70(0.4)$ & $70.56(0.6)$ & $70.57(0.6)$ \\
\hline Ge K $\alpha$ & $29.58(1.4)$ & $30.79(0.4)$ & $30.95(1.0)$ & $29.49(0.4)$ & $29.79(1.0)$ \\
\hline Total & 100.56 & 102.14 & 102.65 & 100.15 & 100.36 \\
\hline
\end{tabular}

Table 4. Analysis of SiGe thick films with element standards

\begin{tabular}{|c|c|c|c|c|c|}
\hline $\begin{array}{l}\text { Sample/ } \\
\text { Ele,Line }\end{array}$ & \multicolumn{2}{|c|}{$\begin{array}{c}\text { Armstrong Cor/LineMu } \\
\text { MACs }\end{array}$} & $\begin{array}{c}\text { Mixed keV } \\
\text { (as in Table 1) }\end{array}$ & \multicolumn{2}{|c|}{ EDS Analysis } \\
\hline SiGe10 & $15 \mathrm{keV}$ & $20 \mathrm{keV}$ & $15,20 \mathrm{keV}$ & $15 \mathrm{keV}$ & $20 \mathrm{keV}$ \\
\hline Si K $\alpha$ & 75.94 & 75.72 & 76.75 & 76.41 & 75.87 \\
\hline Ge K $\alpha$ & 22.42 & 22.90 & 22.95 & 23.12 & 23.03 \\
\hline Total & 98.37 & 98.61 & 99.70 & 99.53 & 98.90 \\
\hline \multicolumn{6}{|l|}{ SiGe25 } \\
\hline $\mathrm{Si} \mathrm{K \alpha}$ & 55.04 & 55.15 & 55.71 & 55.47 & 55.57 \\
\hline $\mathrm{Ge} \mathrm{K} \alpha$ & 43.80 & 44.14 & 44.16 & 44.56 & 44.54 \\
\hline Total & 98.84 & 99.30 & 99.87 & 100.13 & 100.48 \\
\hline
\end{tabular}

